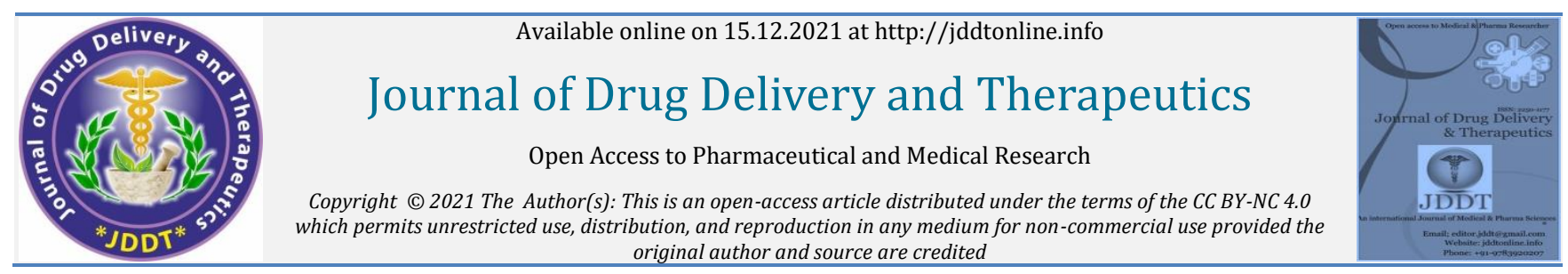

Open Access Full Text Article

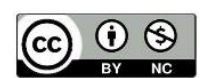

Research Article

\title{
The Effect of Exercise on the Total Leukocyte, Absolute Neutrophil, Lymphocyte and Platelet Counts among Sudanese Football Players
}

\author{
Raheeg Mubark Anwer 1, Nihad Elsadig Babiker*,1,2,3 \\ ${ }^{1}$ Faculty of Medical Laboratory Sciences, National University, Sudan \\ 2 Darfur University College, Sudan \\ ${ }^{3}$ National Center of Neurological Sciences, Sudan
}

\section{Article Info:}

\section{Article History:}

Received 11 September 2021 Reviewed 18 October 2021 Accepted 04 November 2021 Published 15 December 2021

\section{Cite this article as:}

Anwer RM, Babiker NE, The Effect of Exercise on the Total Leukocyte, Absolute Neutrophil, Lymphocyte and Platelet Counts among Sudanese Football Players, Journal of Drug Delivery and Therapeutics. 2021; 11(6-S):26-32

DOI: http://dx.doi.org/10.22270/jddt.v11i6-S.5109

*Address for Correspondence:

Nihad Elsadig Babiker, Faculty of Medical Laboratory Sciences, National University, Sudan

\section{Abstract}

Background: Aerobic exercise induces physiological stress on the body and brings changes in hematological parameters. This study aimed to determine the effect of playing football as an exercise on the total white blood cell count, absolute Neutrophil, lymphocyte and Platelet counts among Sudanese football players.

Material and method: This was a descriptive case control study, done on a number of football players in Khartoum state, Sudan and conducted within the period from August 2021 to October 2021. Three $\mathrm{ml}$ of venous blood samples had been collected from every participant in the study, parameters had been measured and calculated using blood cells counter (Sysmex KX-21N).

Results: When compared the TWBCs, Absolute Neutrophil, Lymphocytes and platelet counts between cases and control there was a significant differences with $(\mathrm{P} \leq 0.05)$. Also there was a significant difference in the case group before and after one hour of exercise with $(\mathrm{P}$ $=0.00)$, and in significant differences between different age groups with $(\mathrm{P} \geq 0.05)$.

Conclusion: Playing football for 1 hour cause a significant increase in the TWBCs, absolute Neutrophils, absolute Lymphocytes and Platelets counts. Age variation has no effect on the measured parameters

Keywords: Football, TWBCs, Neutrophils, Lymphocytes and Platelets.

\section{INTRODUCTION:}

Blood is a body fluid consists of blood cells suspended in blood plasma. Plasma which constitutes $55 \%$ of blood fluid, mostly water ( $92 \%$ by volume), and consist of proteins, glucose, mineral ions, hormones, carbon dioxide, and blood cells. The primary protein in plasma is the albumin, and it has a capability to control the osmotic pressure of blood. 1,2

Blood preforms numerous functions within the body such as ; provide of oxygen to tissues, deliver of nutrients such as glucose, amino acids, and fatty acids, removal of waste like carbon dioxide, urea, and lactic acid, immunological features such as circulation of white blood cells, and detection of foreign material by antibodies coagulation, the response to a broken blood vessel, the conversion of blood from a liquid to a semisolid gel to prevent bleeding, messenger functions, inclusive the transport hormones and the signaling of tissue damage, organization of core body temperature and it has hydraulic functions. 3

White blood cells are vital cellular components of the blood. They're mainly produced within the bone marrow, by a process called leucopoiesis. ${ }^{4}$ White blood cells are a part of the cellular elements of the blood, which are produced from a common, multipotential hematopoietic cell. This progenitor cell has the capacity of self-renewal as well as differentiation into all types of cellular elements, they go through multiple mitotic division cycles before differentiating into mature cells, as progenitor cells undergo maturation they produces the major classes of the cellular elements of the circulating blood: the erythrocytes, leukocytes, and thrombocytes. ${ }^{5}$

On the idea of function, leukocytes can be divided into the granulocytic, monocytic, and lymphoid series. 6 They contain a substantial part of the body's immune system; they destroy and remove old or aberrant cells and cellular debris, in addition to attacking infectious agents and foreign substance. ${ }^{4,7}$

A complete blood count [CBC] is a blood test ordor by physician or other medical Professional which provides information concerning the blood cells and hemoglobin concentrations. ${ }^{8}$ 
Re creational exercise is now part of everyday life style because it is important for maintaining cardiovascular fitness emphasis on improving cardiac input and activity as well as manipulating the immune system for a better and prolonged life. ${ }^{9}$ The total number of white blood cells (WBCs) was increased during and immediately after exercise and both leukocytosis and thrombocytosis occurred in the first 10 min of high-intensity exercise. 20, 22 Neutrophilia may depend on the duration rather than the intensity of the exercise, which also depends on the release of adrenocorticotropic hormone. Intensive short-term exercise resulted in increased leukocytosis which included lymphocytes, granulocytes and monocytes concomitant with alterations in plasma catecholamine levels. Similarly, a short period of recreational vigorous exercise induced significant leukocytosis, which could be due to the release of adrenaline. 10

Many studies have emphasized that exercise has a protective effect on multiple chronic diseases such as; type II diabetes, cardiovascular diseases, cancer, psychological disorders and depression. ${ }^{11}$.

Table (1.1): Normal ranges for TWBCs, Neutrophils, Lymphocytes and platelets in Male and Females of African origin.(24)

\begin{tabular}{|l|l|l|l|l|}
\hline \multicolumn{1}{|c|}{ Parameter } & \multicolumn{1}{c|}{ TWBCs } & Neutrophils & Lymphocytes & Platelets \\
\hline Male & & & & \\
\hline Female & $2.9-8.3 \times 10^{9} / \mathrm{l}$ & $0.8-3.9 \times 10^{9} / \mathrm{l}$ & $1.5-4.3 \times 10^{9} / \mathrm{l}$ & $124-378 \times 10^{9} / \mathrm{l}$ \\
\hline
\end{tabular}

\section{MATERIAL AND METHODS}

This is a descriptive case control study carried out in a number of football yards in Khartoum state, Sudan during the period of August to October 2021.

Inclusion criteria Sudanese football players from different ages and ethnic groups, who are apparently healthy with no history of infections or chronic illness, were included as a cases in this study and apparently healthy non-football players' from different ages and ethnic groups, with no history of infections or chronic diseases, were included as a control.

Exclusion criteria: Individuals complaining from any infection, chronic diseases or receiving any treatment that may affect the measured parameters were excluded from this study.

$3 \mathrm{ml}$ of venous blood samples were gathered from each participant in the study before and after exercise, using sterile disposable syringe by applying aseptic, standardized and non-traumatic vein puncture technique. The samples were collected in glass containers with Ethylene Diamine Tetra-acetic acid (EDTA) anticoagulant, Blood was mixed with the anticoagulant by gently inverting the tubes several times, labeled with name and serial number, transported in cool containers with ice and stored at $4^{\circ} \mathrm{C}$ for subsequent testing. Data was collected from each player using structured questionnaire. The study was approved by the ethical committee of medical laboratory sciences fuculty at the National University.

the blood samples were analyzed using the automated hematological analyzer(Sysmex KX-21N) which works with electrical impedance principle. This instrument provided a detailed report of all blood cells parameters, which will include; total WBCs count, platelets counts and indices, and differential parameters, including; relative and absolute counts of Neutrophil and Lymphocytes. ${ }^{6}$ Data obtained was analyzed using the statistical package of social science (SPSS) program. Statistics will be given as mean_ standard deviation (Mean_SD), the level of $\mathrm{p}<0.05$ was considered as statistically Significant, and results was presented in forms of charts and tables.

\section{RESULTS}

\section{The epidemiological study}

In the present study 50 aerobic exercise players in a number of football were included as case group, $50 \%$ their age (2429 years ), $32 \%$ their age (18-23years) and 18\% their age (30-35 years respectively. In addition, 50 of apparently healthy males were selected as a control group, $40 \%$ their age (24-29 years), $18 \%$ their age (18-23years) and $48 \%$ their age (30-35) years respectively. All of the participants in the study are males $(100 \%)$ (Table 1,2)(fig1, 2).

Table 1: frequency of age groups among case samples

\begin{tabular}{|ccc|}
\hline Age groups & Frequency & Percent \\
\hline $\mathbf{1 8 - 2 3}$ & 16 & $32 \%$ \\
\hline $\mathbf{2 4 - 2 9}$ & 25 & $50 \%$ \\
\hline $\mathbf{3 0 - 3 5}$ & 9 & $18 \%$ \\
\hline Total & 50 & $100 \%$ \\
\hline
\end{tabular}

Table 2: frequency of age groups among control samples

\begin{tabular}{|ccc|}
\hline Age groups & Frequency & Percent \\
\hline $\mathbf{1 8 - 2 3}$ & 20 & $40 \%$ \\
\hline $\mathbf{2 4 - 2 9}$ & 6 & $12 \%$ \\
\hline $\mathbf{3 0 - 3 5}$ & 24 & $48 \%$ \\
\hline Total & 50 & $100 \%$ \\
\hline
\end{tabular}




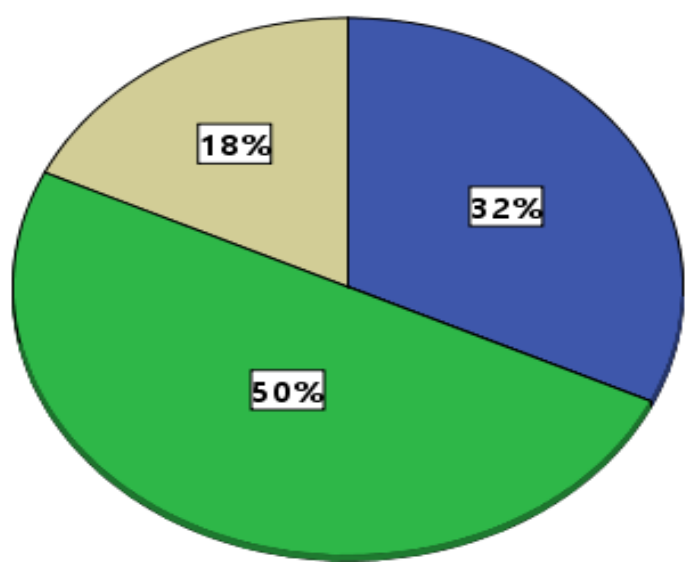

Figure 1: Distribution of Ages in the Case group

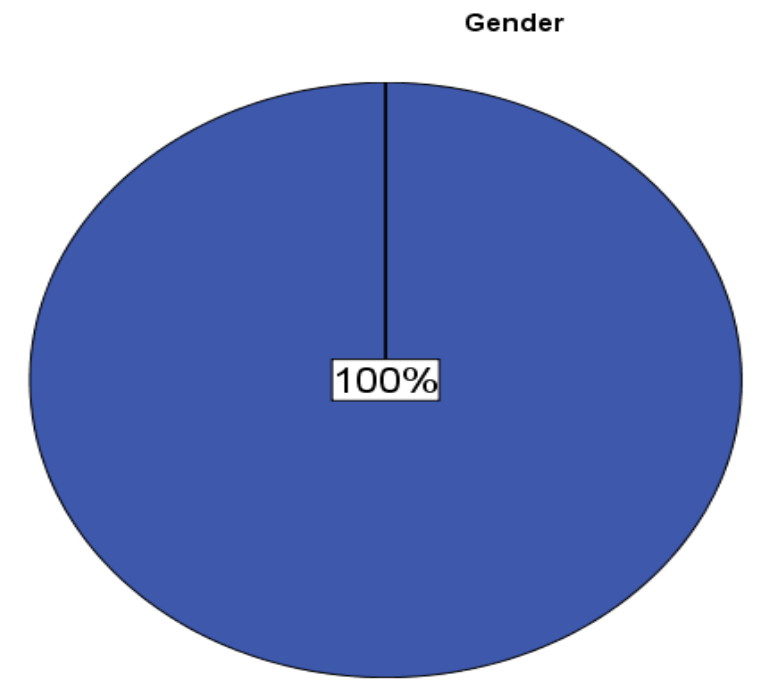

$\square$ Male

Figure 2: Percentage of male gender in the case and control study groups

\section{Hematological Result}

When compared the TWBCs, Absolute Neutrophil, Lymphocytes and platelet counts between cases and control there was a significant differences with $(\mathrm{P} \leq 0.05)$ (table 3)(Fig 3). Also there was a significant difference in the case group before and after one hour of exercise with $(\mathrm{P}=0.00)$ (table 4). In addition to that, when compared the TWBCs, Absolute Neutrophil, Lymphocytes and platelet counts between different age group there was insignificant differences with $(P \geq 0.05$ ) (table 5) (fig 4,5,6,and 7).

Table 3: Mean standard deviation and significance level of test vs. control samples.

\begin{tabular}{|c|c|c|c|c|}
\hline \multicolumn{2}{|c|}{ Parameter } & Mean & \pm P.D & P-value \\
\hline TWBCS & Case & 7.6333 & 1.81391 & $0.017^{*}$ \\
\hline Absolute Neutrophil & Control & 6.7646 & 1.27087 & $0.00^{*}$ \\
& Case & 6.2024 & 1.81549 & 1.35903 \\
\hline Absolute Lymphocyte & Control & 4.6710 & 1.06089 & $0.006^{*}$ \\
\hline Platelets & Conse & 3.0836 & 0.67989 & \\
\hline & Case & 2.5666 & 57.597 & $0.00^{*}$ \\
\hline
\end{tabular}



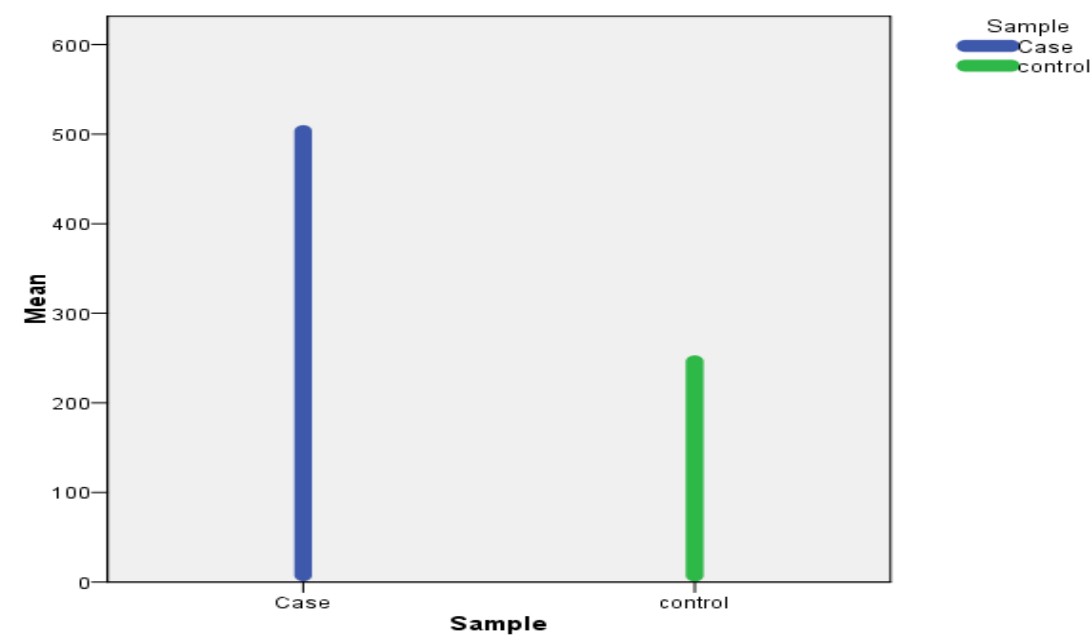

Figure 3: Mean of samples one hour after exercise compared to normal control samples

Table 4: Mean standard deviation and significance level of parameters before and one hour after exercise

\begin{tabular}{|c|c|c|c|c|}
\hline \multicolumn{2}{|c|}{ Parameter } & Mean & IS.D & P-value \\
\hline TWBCs & Before exercise & 6.5720 & 1.75349 & $0.00^{*}$ \\
& After exercise & 7.5600 & 1.81600 & $0.00^{*}$ \\
\hline Absolute Neutrophil & Before exercise & 4.3202 & 1.25071 & $0.00^{*}$ \\
\hline Absolute Lymphocyte & After exercise & 5.1198 & 1.33583 & 1.10244 \\
\hline & Aefore exercise & 1.8818 & 1.29015 & $0.00^{*}$ \\
\hline
\end{tabular}

Table 5: Effect of age variation on the measured parameters

\begin{tabular}{|c|c|c|c|}
\hline \multicolumn{2}{|c|}{ Variable } & Mean Square & P value \\
\hline TWBCs before\& after exercise & Between Groups & 3.404 & 0.337 \\
& Within Groups & 2.900 & 0.912 \\
\hline Neutrophil before\& after exercise & Between Groups & 1.000 & 0.515 \\
\hline Lymphocyte before\& after exercise & Within Groups & 1.864 & 0.423 \\
\hline Platelet before $\&$ after exercise & Wetween Groups & 1.188 & 1.230 \\
& Wetween Groups & 1912.077 & 1792.474 \\
\hline
\end{tabular}




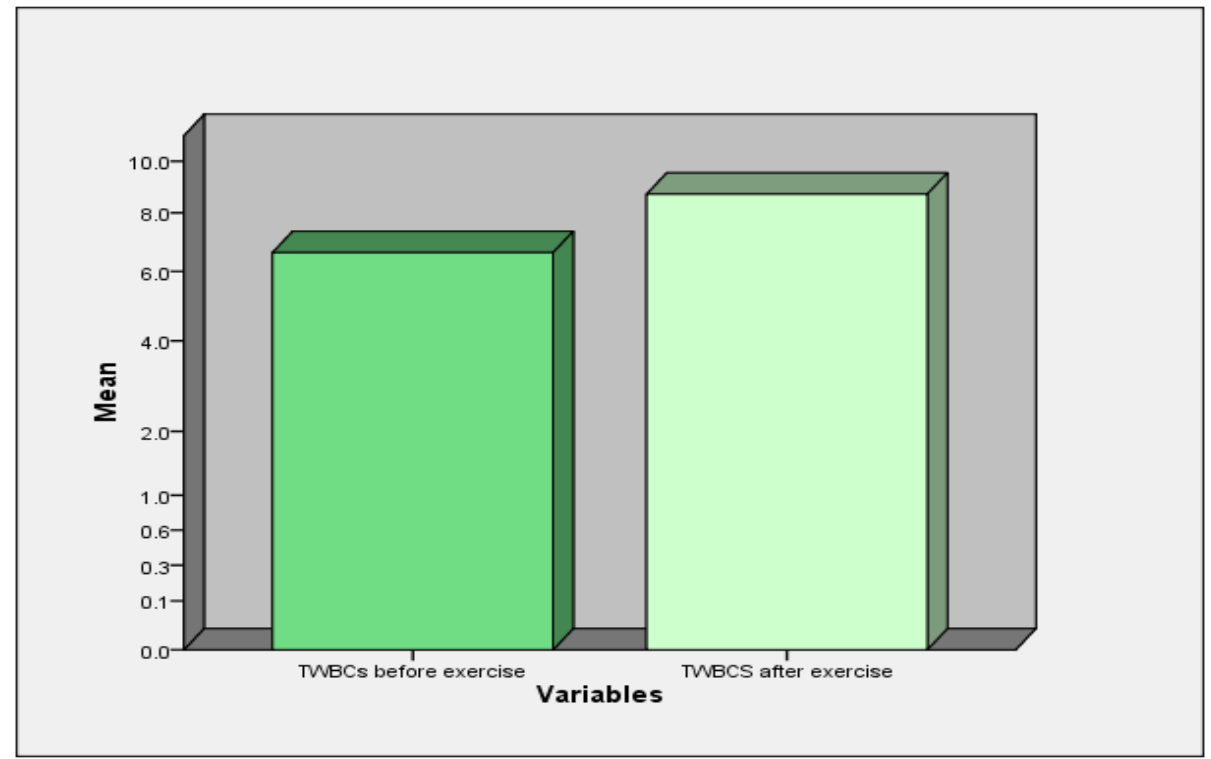

Figure 4: Mean of Total leukocyte counts before/after exercise

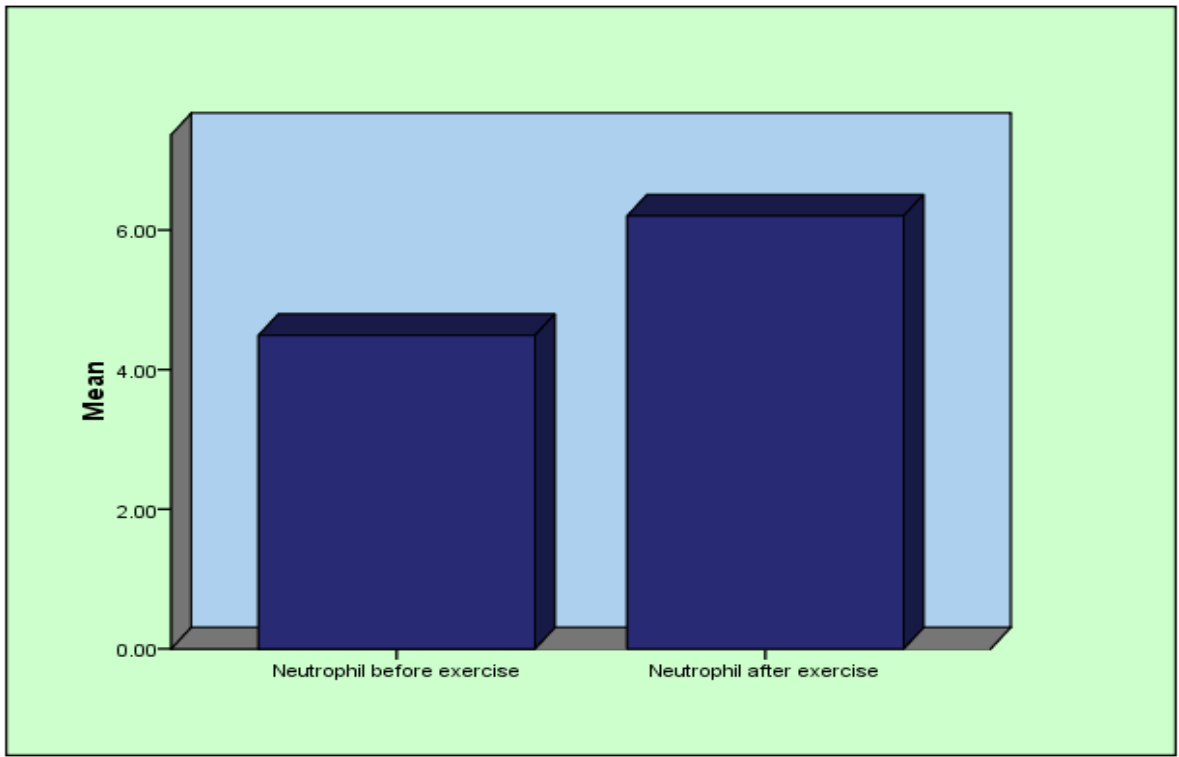

Figure 5: Mean of Neutrophil counts before/after exercise

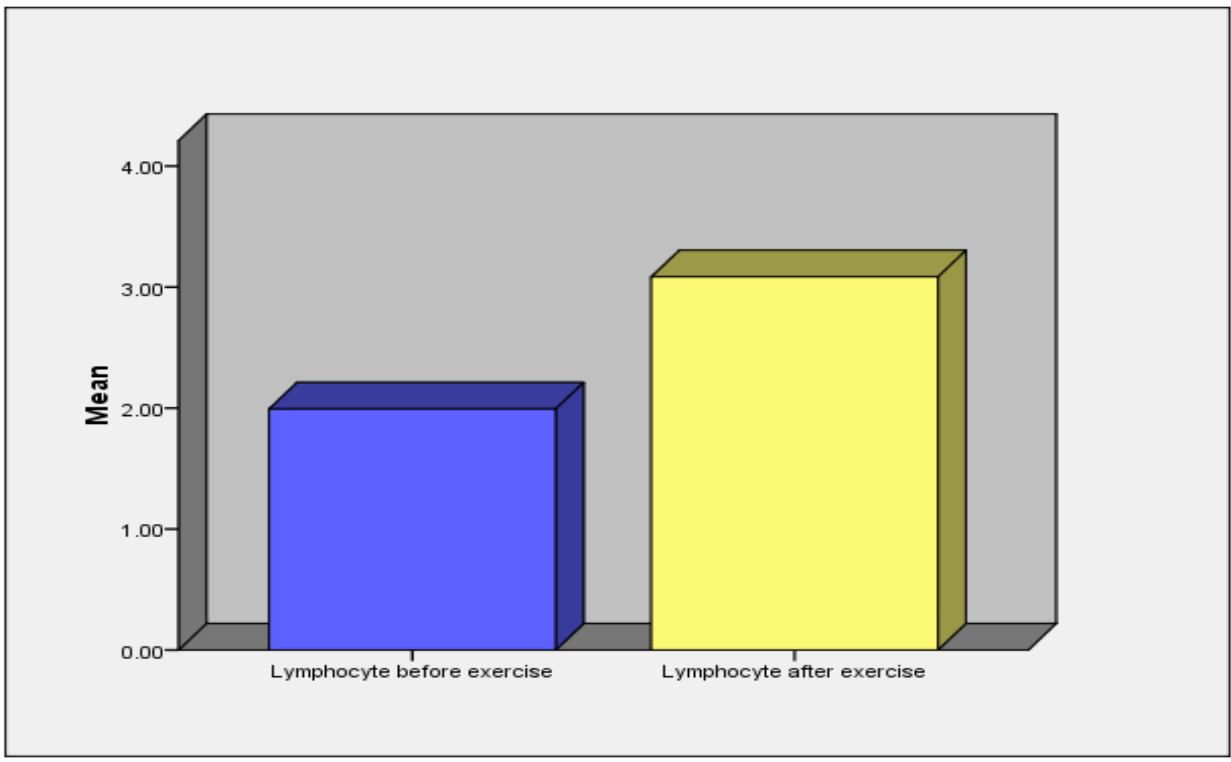

Figure 6: mean of Lymphocyte counts before/after exercise 


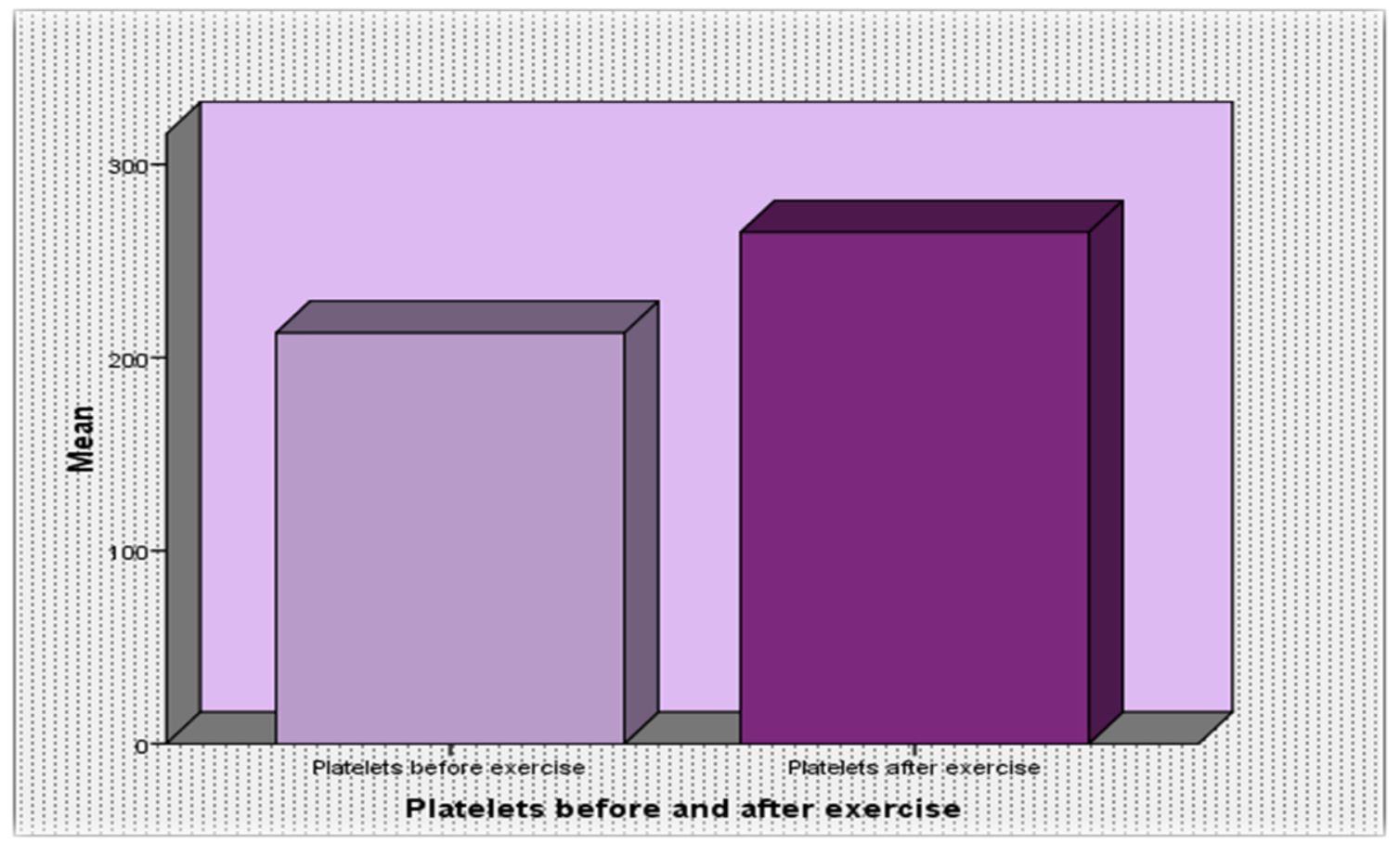

Figure 7: mean of platelet counts before/after exercise

\section{DISCUSSION}

Exercise is well-known to induce an immediate leukocytosis with varying degrees, depending on the intensity and duration of the work. It induces a physiological stress on the body which cause Adrenaline release, as it was proposed by McCarthy DA., that catecholamines produced during exercise act to increase the ratio of circulating to non-circulating leucocytes. ${ }^{4}$

The aim of this study was to observe changes induced by moderate exercise represented by Football, on the leukocytes and platelets factions of the hematological parameters among our young healthy population.

Results showed significant increase before and after one hour of exercise; on the TWBCs, absolute neutrophils and lymphocytes counts ( $\mathrm{P}$ values $=0.00)$, and on platelets count $(\mathrm{P}$ value $=0.00)$. When compared to a control group changes were also significant; on the TWBCs ( $P$ value=0.017), neutrophils $(\mathrm{P}$ value $=0.00)$, on the lymphocytes counts $(\mathrm{P}$ values $=0.006)$ and on platelets $(P$ value $=0.00)$. Also in deferent age groups there was in significant differences with $(\mathrm{P} \geq 0.05)$

These results match with results of a previous study by Kristin et al., which concluded; aerobic exercise leads to a significant increase in TWBCs, absolute lymphocyte and neutrophils counts. ${ }^{12}$ They also link with a study by Robertson et al., on healthy subjects immediately before and at intervals after exercise; subjects developed a lymphocytosis immediately after exercise, which the study justified by the discharge of intravascularly sequestered cells. ${ }^{13}$ Another study with similar findings was done by Lund et al., on two groups of subjects with different aerobic endurance levels to reveal potential variances as a result of physical conditioning; results showed that exercise was associated with an increase in Monocytes, platelets, and granulocyte counts. ${ }^{14}$

A previous study showed that a significant increase in the numbers of segmented neutrophils after exercise was observed, lymphocyte numbers were also increased, whereas no increase in the numbers of monocytes was observed. These results could be due to the recruitment of cells from the bone marrow. It was previously observed that CXCL1\interleukin (IL)-8 was increased in the blood circulation of the athletes performing exercise. 15

Increased CXCL8\IL-8 concentration could demonstrate the higher numbers of neutrophils observed.(30)furthermore, different patterns of cell accumulation in the blood circulation were observed after 5 min intense exercise. This increase might be due to potentiating the sheer blood flow that happens during this type of exercise. ${ }^{16}$

The effect of exercise on the immune system, was demonstrated in a study by Gray et al., which estimated that exercise not only affects the leukocyte count, but function as well; results showed an increase in blood leukocytes, early and rapid increase after a session of exercise was assumed to be a result from lymphocytosis caused by recruited lymphocytes both CD4+ and CD8+ T-cells to peripheral blood, as well as detachments of neutrophil and monocytes from blood vessels caused by a high shear stress and catecholamines production, while the prolonged late increase seems to be induced by increase in cortisol levels that stimulated the release of neutrophils from bone marrow. However, these responses differ in extent, interval course or duration depending on exercise type, as well as body composition and cardiorespiratory fitness of the participants. ${ }^{15}$ finally Wang et al., demonstrated the impact of exercise on platelet function and how it reduces the risk of cardiovascular disorders; by measuring platelets adhesion and aggregation in response to different agonists, before and after exercise. Results presented that strenuous exercise increased platelet adhesiveness and aggregability in both healthy subjects and patients with stable angina. ${ }^{17}$

\section{CONCLUSION}

Playing football for 1 hour cause a significant increase in the TWBCs, absolute Neutrophils, absolute Lymphocytes and Platelets counts. Age variation has no effect on the measured parameters. Further studies are needed with large sample size and to cover other area. 


\section{REFERENCES}

1. Gabriel H, Kindermann W. The acute immune response to exercise: what does it mean? Int J Sports Med 1997; 18 Suppl 1:S28-S45. https://doi.org/10.1055/s-2007-972698

2. Gray AB, Telford RD, Collins M, Weidemann MJ. The response of leukocyte subsets andplasma hormones to interval; exercise. Med Sci Sports Exerc 1993; 25:1252-1258. https://doi.org/10.1249/00005768-199311000-00008

3. McCarthy DA, Macdonald I, Grant M, Marbut M, WatlingM, Nicholson S, Deeks JJ,

Wade AJ, Perry JD. Studies on the immediate and delayed leucocytosiselicited by brief (30-min) strenuous exercise. Eur J ApplPhysiolOccupPhysiol 1992; 64: 513-517. https://doi.org/10.1007/BF00843760

4. McCarthy DA, Dale MM. The leucocytosis of exercise.A review and model. Sports Med 1988; 6:333-363. https://doi.org/10.2165/00007256-198806060-00002

5. McCarthy DA, Perry JD, Melsom RD, Dale MM. Leucocytosis induced by exercise. Br Med J (Clin Res Ed) 1987; 295: 636. https://doi.org/10.1136/bmj.295.6599.636

6. Wintrobe MM. Wintrobe's clinical hematology.Lippincott Williams \& Wilkins; 2008.

7. Dacie ,J.V. and Lewis ,M. Practical Hematology; 11th edi.; london; Elsevier Limited; chapter 2011; 3:21- 35.

8. Büttner P, Mosig S, Lechtermann A, Funke H, Mooren FC. Exercise affects the gene expression profiles of human white blood cells. Journal of applied physiology. 2007 Jan; 102(1):26-36. https://doi.org/10.1152/japplphysiol.00066.2006

9. Maes M, Lambrechts J, Bosmans E, Jacobs J, Suy E, Vandervorst C, De Jonckheere C, Minner B, Raus J. Evidence for a systemic immune activation during depression: results of leukocyte enumeration by flow cytometry in conjunction with monoclonal antibody staining. Psychological medicine. 1992 Feb; 22(1):4553. https://doi.org/10.1017/S0033291700032712

10. Pickering AD, Pottinger TG. Cortisol can increase the susceptibility of brown trout, Salmotrutta L., to disease without reducing the white blood cell count. Journal of fish biology. 1985
Nov; 27(5):611-9. https://doi.org/10.1111/j.10958649.1985.tb03206.x

11. Frodermann, V., Rohde, D., Courties, G., Severe, N., Schloss, M. J., Amatullah, H., McAlpine, C. S., Cremer, S., Hoyer, F. F., Ji, F., van Koeverden, I. D., Herisson, F., Honold, L., Masson, G. S., Zhang, S., Grune, J., Iwamoto, Y., Schmidt, S. P., Wojtkiewicz, G. R., Lee, I. H., Nahrendorf, M. Exercise reduces inflammatory cell production and cardiovascular inflammation via instruction of hematopoietic progenitor cells. Nature medicine, 2019; 25(11):1761-1771. https://doi.org/10.1038/s41591-0190633-X

12. Kristin L Sand , Torun Flatebo , Marian bergeanderrsen , Azzam A Maghazachi, Effects of exercise on leukocytosis and blood hemostasis in 800 healthy young females and males , world journal of experimental medicine 2013; 3(1):11 https://doi.org/10.5493/wjem.v3.i1.11

13. Robertson, A. J., Ramesar, K. C., Potts, R. C., Gibbs, J. H., Browning, M. C., Brown, R. A., Hayes, P. C., \& Beck, J. S. The effect of strenuous physical exercise on circulating blood lymphocytes and serum cortisol levels. Journal of clinical \& laboratory immunology, 1981; 5(1).

14. Lund, T., Kvernmo, H. D., \&Osterud, B. Cellular activation in response to physical exercise: the effect of platelets and granulocytes on monocyte reactivity. Blood coagulation \&fibrinolysis : an international journal in haemostasis and thrombosis, 1998; 9(1):63-69. https://doi.org/10.1097/00001721-199801000-00008

15. McCarthy DA, Dale MM, The leukocytosis of exercise, Sport medicine 1988; 6(6):333-363. https://doi.org/10.2165/00007256-198806060-00002

16. Ruegsegger, G. N., \& Booth, F. W. Health Benefits of Exercise. Cold Spring Harbor perspectives in medicine, 2018; 8(7):a029694. https://doi.org/10.1101/cshperspect.a029694

17. Wang JS, Jen CJ, Kung HC, Lin LJ, Hsiue TR, Chen HI. Different effects of strenuous exercise and moderate exercise on platelet function in men. Circulation. 1994 Dec; 90(6) https://doi.org/10.1161/01.CIR.90.6.2877 